after defervescence the pulse remained rapid and the patients were depressed. In 4 cases only was there serere pharyngitis ; in 29 others there was increased redness of the mucous membrane of the throat and mouth, but it was not attended by swelling, was not marked, and did not last long. Only 1 patient died, a delicate child convalescent from scarlet ferer. The suggestion that the epidemic might have been an aberrant form of mumps was considered, but was rejected; neither the parotid nor any other salivary glands were affected in any of the cases; no case of ordinary mumps occurred in the district during the time these cases of glandular fever were occurring, and 57 of the 96 children had mumps before, or at some date after, the fever. A dull flush of the skin was noticed, but no eruption in any case, and it is difficult to believe that so many cases of rubella could have occurred without the rash being noticed in any of them.

The incubation period cannot be stated positively. Hoerschelmann ${ }^{6}$ thonght it was usually from eight to ten days in his cases, with extremes of five and fifteen days. Park West states that "many more children came down on the seventh day after exposure than upon any other day."

As to the pathology of the condition there is, in the absence of any bacteriological investigations, much room for difference of opinion. Comby ${ }^{\gamma}$ suggests that it is clue to "an attenuated streptococcic infection, of which the point of entry is probably the surface of the tonsils." He would therefore appear to be opposed to the view that the condition should be considered an acute specific infection, and this seems to be the view also of Ashby and Wright. ${ }^{8}$ Comby, however, relies, I gather, largely upon the observations of Neumann, who found stapbylococci in certain glands which suppurated, and Comby also speaks of cases in which suppuration occurred. All other writers, however, comment on the absence of suppuration as a characteristic of the disease. The constant presence of obstinate constipation led $\nabla$. Starck ${ }^{3}$ to advance the theory that the general symptoms and the adenitis might be due to infection derived from the intestines or to the absorption of a toxin from the retained fæces. Dr. Henry Koplik, in the discussion at the New York Academy of Medicine, suggested that the earlier affection of the glands of the left side of the neck, which has struck most of those who have published notes on the disease, might be due to passage of the infective agent from the thoracic duct to the glands on the same side. On the whole, however, it seems probable that the infective agent, whatever it may be, obtains entrance by the pharynx or tonsils without producing a local lesion there, as is sometimes the case with the bacillus tuberculosis.

The condition presents certain analogies to the "nonvenereal bubo," which has recently attracted a good deal of attention in the Far Fast, and has been the source of not a little perplexity to the medical officers of the army and navy. ${ }^{10}$ In connexion with the theory that the glandular fever of childhood is due to intestinal infection and tozemia it is interesting to note that Surgeon-Major Skinner ${ }^{11}$ has suggested that as the "non-venereal buboes" in the cases he observed invariably occurred in the inguinal glands, and as the patients always had irregular action of the bowels and sometimes dysentery, and in others apparently constipation, the enlargement of the inguinal glands may be due to secondary infection from the mesenteric lymph glands.

Since the body of this paper was written I have read with much interest Dr. Cantlie's statement, in his address published in The LANCET ${ }^{12}$ that in Hong-Kong he had become familiar with an idiopathic glandular enlargement occurring in children in an epidemic form. The enlargement, he states, involved usually only one gland in the neck over the sterno-mastoid, but at its anterior border. Apparently, therefore, the adenitis affected the superficial and not, as in Pfeiffer's "Drüsenfieber," the deep cervical lymphatica. Whether this difference is important, and whether the Hong.Kong cases are more nearly allied to the form with which I bave been dealing, or to "pestis minor" it would be useless to speculate, but the observation is interesting and may turn out to be of much epidemiological importance.

Though the pathology of glandular fever is unknown, it is of practical consequence to recognise that children are

Jahrbuch fur Kinderheilkunde, Band xxxviii., s. 35.

${ }^{7}$ La Médecine Infantile, tome i.,p. 1.:

8 The Diseases of Children, London, 1896, p. 255.

16 Conf. Godding, Brit.Med. Jour., Sept. 26th, 1896, p. 842 . It appears from his cases and remarks that suppuration is rare.

Brit. Med. Jour. Jan. 9th, 1897, p. 78 .

Brit. Med. Jour. Jan. 9th, 1897, p. liable to an affection such as I have endeavoured to describe; that it is communicable; and that, though acute and accompanied often if not usually by high temperature, it is almost invariably benign, and does not lead to suppuration of the affected glands; but that it leaves behind it marked anæmia and general deterioration of health from which the child does not completely recorer for a month or two.

There is one other point in which the affection resembles a specific fever. Treatment does not, so far as I have observed, or so far as can be gathered from the literature, exercise any influence over the course or duration of the malady. A cold compress to the neck or, in the more severe cases, belladonna fomentations relieve the local symptoms but do not prevent the onset of adenitis on the opposite side. The bowels respond readily to laxatives, but the constipation soon returns. Purgatives, such as calomel, do not produce any more permanent effect, and Dr. Park West states that in some of the cases in which resort was had to this practice it seemed to be responsible for greater depression and a more prolonged convalescence.

Harley-street, w.

\section{A CASE OF EXCISION OF THE LPPER HALF OF THE RECTUM FOR CANCER.}

BY J. JACKSON CLARKE, M.B.LOND., F.R C.S. ENG., ASSISTANT SURGEON TO THE NORTH-WEST LONDON HOSPITAL; PATHOLOGIS'T AND CURATOR OF THE MUSEUM AT ST. MARY'S HOSPITAK.

SINCE 1885, when Kraske described a procedure by whici the upper part of the rectum and as much of the sigmoid flexure as might be wished could be removed, this operation has been frequently performed. In this country Swinford Edwards, ${ }^{1}$ Paul, ${ }^{2}$ and Littlewocd ${ }^{3}$ have published cases. The present position of the treatment of rectal cancer has been recently dealt with by Heidenhain, who says: "The rule that rectal cancer can only be dealt with successfully when the upper limit of the growth can be reached by the finger introduced at the anus no longer holds good. The only local contra-indication to the operation is the extension of the growth to the prostate, bladder, or ureter." As a contribution to the literature of the subject the following case may be of interest.

The patient, a man aged fifty-one years, was sent to me at the North-West London Hospital on Dec. 5th, 1895. He had had no important illness until he began to suffer with intestinal symptoms five months before he came to me. First he noticed streaks of blood in the stools ; then followed attacks of troublesome constipation which alternated with diarrhœa. On digital examination from the anus the lower margin of a typical cancerous ulcer could be feit. It appeared to be about an inch above the base of the prostate. Although pale and thin the patient appeared to be sound save for the local disease. In order to make sure that the growth had not extended to the bladder or vreters a median abdominal incision was made on Dec. 19th, and it was found that though the growth was of considerable size it had not extended through the peritoneal aspect of the bowel and was moveable. The median opening was then closed and a left inguinal colotomy done; the sigmoid was drawn well down and its uppermost portion was fixed in the wound. The bowel was opened on the fifth day. Both the median incision and the colotomy wound were firmly united on the tenth day. It was found that though most of the fæces escaped by the colotomy opening still some went down by the rectum, and no means we could devise were found to obviate this. I had performed the operation by Harrison Cripps's rather than by Maydl's method, because the latter might take up too much of the sigmoid and so render it difficult to drew down the rectum later. An attack of influenza, which weakened the patient, delayed the next step. On Jan. 18th, when the patient was well again, he was anæsthetised and placed on the left side An incision was made from the tip of the coccyz. The lower part of the incision lay in the middle line, and the upper inclined to the left edge of the sacrum below the

1 Medical Soniety's Proceedings, 1891, No. 48, p. 942

Brit. Med. Jour., March 9 th, 1895

4 Fortschritte der Medicin, Band xir., 1896. 
posterior inferior spine. The coccyx and the tip and the eft edge of the sacrum as far as the level of the third sacral foramina were removed. In doing this the sacro-sciatic ligaments, some fibres of the gluteus maximus, the left lateral, and the median sacral arteries were divided. There was smart hæmorrhage, which yielded to pressure of cloths, wet with hot carbolic lotion. The posterior surface of the rectum was now exposed, and it was found that the lower end of the growth was opposite the fourth sacral vertebra. The peritoneum was opened on each side of the bowel below the growth and the affected part of the bowel was drawn down into the wound; the fat and glands in the hollow of the sacrum having been removed indiarubber tubes were passed round the bowel above and kelow the growth and the section of the bowel including the growth and three-quarters of an inch of sound gut above and below it were removed. The divided ends of the rectum

FIG. 1.

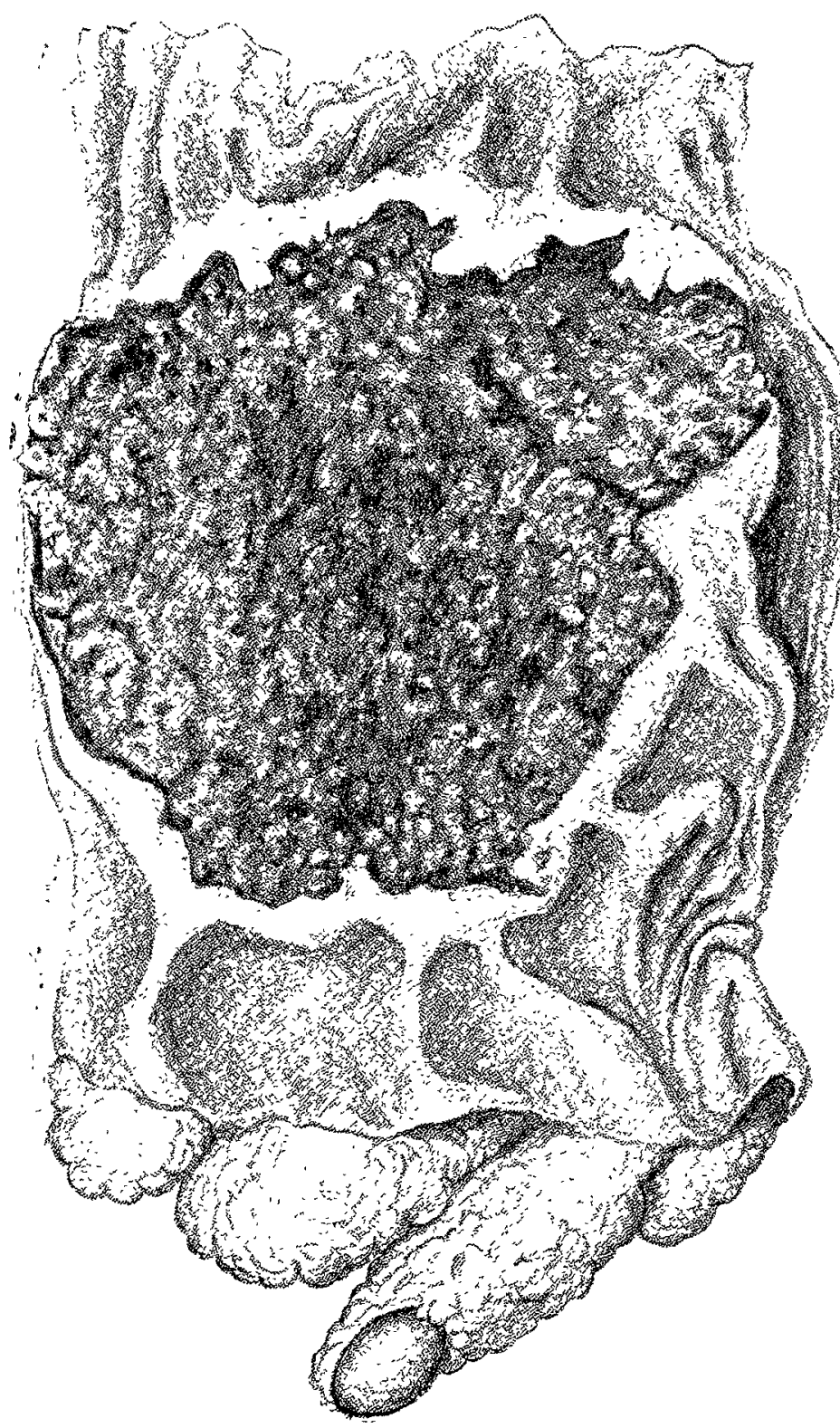

Shows the appearance of the excised segment of bowel from the front. A gland is seen in the fat at the lower end of the specimen. (Natural size.)

in the anterior three-fourths of the circumference were carefully united by silk stitches, which passed through the whole thickness of the gut, the posterior fourth being closed by Lembert's sutures. The peritoneum was then stitched in front of the rectum, and the skinwound was stitched in its upper three-fourths, the lower fourth being packed with sal-alembroth gauze. There was nothing noteworthy in the progress of the case until the fourth day, when a distinct rise of temperature $\left(103^{\circ} \mathrm{F}\right.$.) was observed, and it was found that some of the Lembert's sutures had given way, allowing the escape of fæcal matter. The wound was cleansed and glycerine and iodoform syringed into it. After this the wound healed rapidly by granulation, but left a large fistula. Two attempts to close the latter by a plastic operation having failed a linear proctotomy was done under cocaine infiltration in order to join the fistula and anus together. There remained only to close the artificial anus in the groin. After freshening the edge of the mucous membrane at the opening the latter was closed by a continuous silk suture passing through mucous membrane alone. The peritoneum was next opened all round the orifice and a row of Lembert's sutures placed outside the continuous suture. After this had been done a high-pitched, whistling note was heard, due to wind escaping from the bowel, so a second row of Lembert's sutures was placed outside the first. The bowel was then dropped back into the peritoneal cavity and the parietes were closed over all. The patient only complained of not being allowed enough to eat after this operation. I showed the patient at the North-West London Clinical Society on Oct. 21st, 1896, nine months after the operation. The patient was then in perfect health and for the last three months had been working full time as a carpenter, his employment being in making the roof of a house eighty feet high. He has one

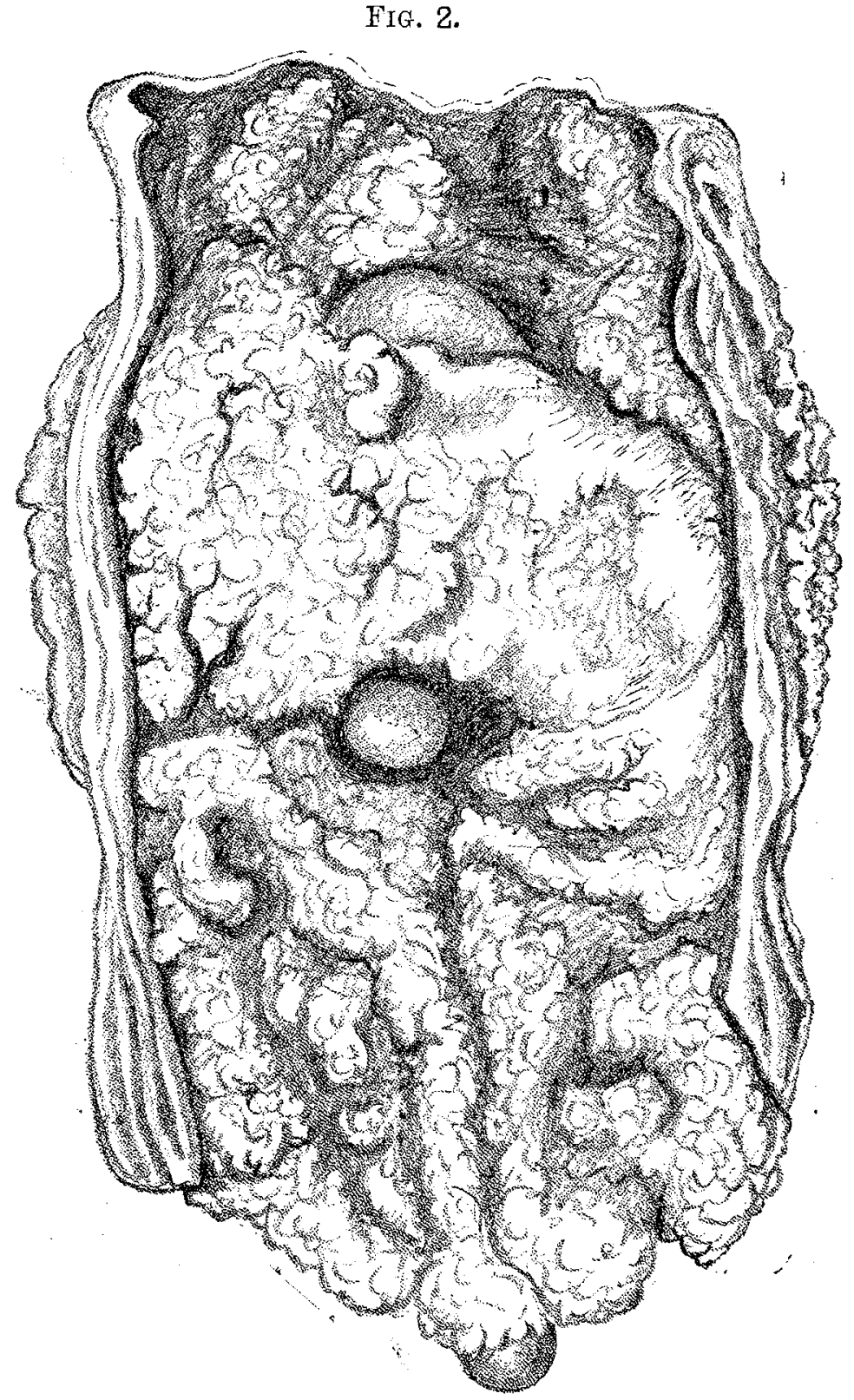

Shows the posterior view. There is an enlarged gland embedded in fat opposite the middle, ard a second at the embedded in fat opposite the middle, ard a
lower end, of the preparation. (Natural size.)

good motion daily and by means of a hollow rubber colotomy plug suspended by rubber bands the opening below the sacrum is comfortably closed. He can relieve himself of flatus without removing the plug. I have to thank my senior colleague for much valuable counsel in the conduct of the case and Mr. Stroud Horsford, house surgeon, for great care and diligence in watching the case.

I am informed by Dr. W. M. Whittaker, who put the case in my hands, that he saw the patient a month ago, eleven months after the removal of the growth, in apparently perfect health.

Remarks.-1. The preliminary exploratory operation. In most cases this would be advisable, as in my opinion it is, with few exceptions, in all cases of cancer of the colon. The information thus gained may decide as to whether a palliative or a radical operation is to be done. In many cases the growth is adherent to neighbouring parts, and any tracticn 
results only in rupturing the bowel and allowing fæcal matter to escape into the peritoneal cavity. Such a condition can only be ascertained by an exploratory operation, the only contra-indications to which are (1) when the growth can be fully explored from the anns and (2) when acute obstruction is present and the position of the block is localisable. 2. The preliminary colotomy. In the case under consideration this proved to be almost useless, and the experience suggests that unless necessary to relieve distension of the bowel it would be better omitted. 3. The operation. The great drawback is the tendency to the formation of a fistula. This is not due to any want of vitality in the rectal tissues, but to the fact that the state of the patient towards the end of the operation does not usually allow time for doing a linear proctotomy and then carefully stitching the ends of the bowel by Maunsell's method. If some method safer than that by Murphy's button and equally rapid could be applied there need be no hesitation in closing up the whole wound, and then in conditions such as that described above I should be inclined to preserve the coccyx by turning it down in a skin flap and to apply one of the methods of osteoplastic section of the sacrum, so that no important muscular or ligamentous attachments need be interfered with.

old Cavendish-street, $\mathbf{W}$.

\section{THREE CASES OF LEAD POISONING, \\ WITH A NOTE ON A SIMPLE METHOD FOR THE DETECTION OF LEAD IN ORGANIC} FLUIDS.

BY JOHN HILL ABRAM, M.D. LoND., M.R.C.P., ASSISTANT PHYSICIAN TO THE LIVERPOOL ROYAL INFIRMARY ; ASSISTANT TO THE PROFESSOR OF PATHOLOGY, UNIVERSITY COLLEGE, IIVERPOOL.

(FROM THE CHEMICAL PATHOLOGY DEPARTMENT, UNIYERSIIX COLLEGE, LIVERPOOL.)

I HAVE had the opportunity during the past year of observing three cases of lead poisoning which are of some interest. The following is a condensed report of the cases, two of which were of the cerebral type and were under my care in the Liverpool Royal Infirmary.

CASE 1.-A man, aged twenty-six years, was admitted on July 2nd, 1896, suffering from "choky" pain in the abdomen, cramps in the legs, and fits. He had been a house painter for eleven years. He stated that he was temperate. In August, 1895, when working on the interior of a church, he had an attack of colic and eight fits. In December, 1895, while painting on board ship, he again had colic and four fits. The present illness began while he was working on the outside of a church. He was seized with pain in the abdomen, walked home with difficulty, and at once went to bed. He had several fits before his admission into the Infirmary. The patient was a well-nourished man, slightly anæmic. He was in a very collapsed condition, the pupils were small, and did not react to light. $\mathrm{He}$ complained of temporal headache and of sleeping badly. The legs and feet were painful and there was some tenderness on pressure. No distinct wrist-drop was present, though there seemed to be some extensor weakness. The plantar reflexes were active; the knee-jerks were absent. There was no optic neuritis. The teeth were poor and ill-kept. A wellmarked lead line was present. The breath was very foul, the tongue was coated, and there was marked thirst. The bowels had not acted for forty-eight hours. There was general pain in the abdomen, which was relieved by steady pressure. The radial artery was not thickened and the pulse showed rather poor tension: There was no hypertrophy of the heart. The specific gravity of the urine, which was loaded with albumin, was 1025 . It contained no sugar or casts. On the night of admission the patient was delirious, and on July 3rd he had a typical epileptiform convulsion, in which the tongue was bitten, and urine passed. He had two similar fits in the course of the day. On the 4th the bowels were cleared out by an enema and kept acting by saline purgatives. From this time he had no further return of the pains or fits and he left the hospital on July 13th practically well. The urine, I may add, was free from albumin. At no time was there any œedema.
CASE 2.-A man, aged thirty-three years, was admitted or Sept. 8th, 1896, for colic. He had been a plumber all his working life. For the last four years he had had repeated attacks of colic, usually accompanied by vomiting. For the last year he had had headache with the attacks. On admission he was found to be emaciated and anæmic. There was no cedema; the muscles were flabby; there was nc paralysis; the knee-jerk was present; and there was nc headache or optic neuritis. The patient slept badly. His teeth were poor and there was a well-marked blue line. $\mathrm{He}$ had pain in the abdomen, which was relieved by pressure and not aggravated by taking food. The bowels had been costive for three days. Vomiting was a troublesome feature of the case ; the romited matter was frothy, green, sour-smelling, and contained lead. The urine was of specific gravity 1011, neutral, and contained a trace of albumin and lead. The urea amounted to 400 grains per diem. He remained in this condition in spite of treatment (no iodide of potassium was given) until the 24th, when he was found to have become semi-comatose. On the 25 th he had slight hiccough. The coma gradually deepened and he died on Oct. 1st.

Necropsy.-Slight thickening of the dura mater along the superior longitudinal fissure was found. The sub-arachnoic fluid was excessive. The brain appeared to be healthy. The lungs were congested and oedematous. The heart was normal. The mucous membrane of the stomach was dark in colour and deeply congested. The liver was rather firm and the kidneys were slightly fibroid. Microscopic examination of the liver revealed a slight amount of degeneration in the cells. In the kidney there was a slight interstitial and chronic inflammation. A chemical examination of some of the organs was made by Mr. Marsden and myself in the usual manner, and Dr. Kohn kindly determined the exact amount of lead present by the electrolytic method. The results of our examination may be contrasted with those obtained in Dr. Davidson's case ${ }^{1}$ and the first reported in Thorpe's. "Dictionary of Applied Chemistry" as follows:-

\begin{tabular}{|c|c|c|c|c|c|c|c|c|c|c|}
\hline Bra & & & $\cdots$ & $\begin{array}{l}\text { Thorpe } \\
29 \cdot 9\end{array}$ & $\begin{array}{c}\mathrm{D} \\
\ldots \ldots . .\end{array}$ & $\begin{array}{l}\text { avids } \\
29 \cdot 9\end{array}$ & $\begin{array}{l}\text { n. } \\
\ldots \ldots . .\end{array}$ & $\begin{array}{c}\text { Abra } \\
20\end{array}$ & & illion. \\
\hline Grey mat & tter & $\ldots$ & $\ldots$ & 40.9 & ...... & - & ....... & 22 & , & , \\
\hline White ma & atter & c... & $\ldots$ & $18 \cdot 9$ & $\ldots \ldots$ & & $\ldots . .$. & 18 & ", & ", \\
\hline Civer... & $\ldots$ & ... & $\ldots$ & $47 \cdot 7$ & ...... & - & ...... & 8 & , & \\
\hline Kidney & $\ldots$ & ... & $\ldots$ & $15 \cdot 5$ & ...... & - & …. & 2 & $"$ & \\
\hline Stomach & $\ldots$ & $\ldots$ & $\ldots$ & 一 & $\ldots \ldots$ & - & ....... & 13 & ," & , \\
\hline
\end{tabular}

The similarity of the amount of lead found in the three cases is striking as regards the brain, but the disagreement in the case of the liver and kidney is very marked and I can offer no explanation for it.

CA8E 3.- One of my colleagues at University College, who had been working with red lead, suffered from griping pain in the abdomen and slight diarrhoea. The urine was found to contain lead. I report this trivial case for reasons I shall give in the last paragraph of my paper.

Cases 1 and 2 are examples of the cerebral forms of lead poisoning, the first the epileptiform and the second the comatose variety. As is not unfrequent in these cases colic was present. A feature of Case 1 - viz., the contracted insensitive pupils-has been noted in encephalopathia saturnina by Tanquerel des Planches. ${ }^{2}$ The general prognosis, as given by Tanquerel, that the epileptiform variety is more dangerous than the comatose is just reversed in my two cases. The treatment adopted in both cases was expectantthat is to say, the further ingestion of lead was checked for the time at any rate, milk diet was given, and the bowels kept open by saline purges. In Case 2 various remedies were tried to relieve the vomiting. In neither case was iodide of potassium given, so that "unlocking " of fixed leac cannot be given as the cause of the fatal coma of Case 2 I lay stress upon this, as iodide of potassium is alleged to give rise to cerebral symptoms in this way in rare cases The expectant treatment was adopted in consequence of Tall querel's statement that, in cerebral lead poisoning at any rate, it gives far better results than a vigorous line of treatment blistering, venesection, and so forth. Careful questioning of the patients and relatives brought to light no trace of any neurotic inberitance, so that I can offer no suggestion as to the reason why these two patients should have suffered from cerebral symptoms. The considerable quantity of albumin present in the urine in Case 1. must, I think, be attribute to the convalsions, as it speedily disappeared when they

The Liverpool Medico-Chirurgical Journal. July, 1896. 2 Lead Disease, Dana's transl., 1848. 